Research Article

\title{
Fragility of Bridge Columns under Vehicle Impact Using Risk Analysis
}

\author{
Kyeongjin Kim $\mathbb{D}^{1}$ and Jaeha Lee $\mathbb{D}^{2}$ \\ ${ }^{1}$ Department of Civil and Environmental Engineering, Korea Maritime and Ocean University, Busan 49112, Republic of Korea \\ ${ }^{2}$ Department of Civil Engineering, Korea Maritime and Ocean University, Busan 49112, Republic of Korea
}

Correspondence should be addressed to Jaeha Lee; leonlee397@gmail.com

Received 30 July 2019; Accepted 18 January 2020; Published 14 February 2020

Academic Editor: Mariano Angelo Zanini

Copyright (c) 2020 Kyeongjin Kim and Jaeha Lee. This is an open access article distributed under the Creative Commons Attribution License, which permits unrestricted use, distribution, and reproduction in any medium, provided the original work is properly cited.

\begin{abstract}
In this study, risk analysis was conducted to evaluate the vulnerability of bridge columns to vehicle impact. A three-step risk analysis procedure was used. The first step involved a Preliminary Risk Analysis (PRA), which was an initial screening step to determine whether a bridge column requires second-step analysis or not. The second step was a Simplified Risk Analysis (SRA), which involved determining the level of risk (low, moderate, or high) for a bridge column. The third step comprised a Detailed Risk Analysis (DRA). Computer simulation was based on the results of SRA. In this study, the risk level of 8,267 bridges in South Korea was evaluated, and a resulting total of 58 bridge columns in the Risk Level High (RLH) category were selected as a result of SRA. These bridge columns were classified into five types based on their slenderness ratio. Using these five types of bridge column, DRA was conducted. As expected, larger deformations of the bridge column were observed if the vehicle velocity and slenderness ratio were both increased. Using the bridge columns in the categories of response high and response moderate under vehicle impact, fragility curves were proposed using statistical data of material strength and the few results of the numerical analysis.
\end{abstract}

\section{Introduction}

Bridges are important pieces of infrastructure that can help with the mobility of goods and people. Damaged bridges, however, pose a lot of risks. According to Sharma et al. [1], the largest hazard factor for bridge collapse was flooding, and the second largest hazard was found to be vehicle collision. One example of the damage that can be caused by a vehicle hitting a bridge column can be seen in Figure 1. Every bridge column has a different vulnerability depending on its dimensions and locations. For designing bridge columns and to find the vulnerability of any bridge column under vehicle impact, risk analysis should be performed that takes account of factors such as service life, safety level, and distance from industrial areas.

The risk analysis using risk-based methodology defines hazards that cause structural damage due to many factors [2]. This methodology uses available information, such as height, diameter, distance from industrial areas, and distance from other roads, to evaluate vulnerability and level of damage. The methodology can finally suggest strategies of restoration and maintenance against any possible risk.

Min et al. [3] performed vehicular collision risk analysis of highway bridge columns. They defined both maintenance and repair costs as importance factors for performing risk analysis. However, in the case of the risk analysis for a bridge column under vehicle impact, these cost factors could be ignored for the simplification of the risk analysis.

In our study, a total of 8,425 bridge columns were investigated. The dimensions and locations of each of the bridge columns were considered as factors for estimating the vulnerability and occurrence of vehicle impact. Based on the estimated vulnerability and occurrence, typical types of highway bridge column were selected. The details regarding the dimensions and locations of the bridge columns are explained in a later section.

Simulations of the bridge column truck collisions for evaluation of the selected bridge columns were then conducted as part of a detailed risk analysis. 


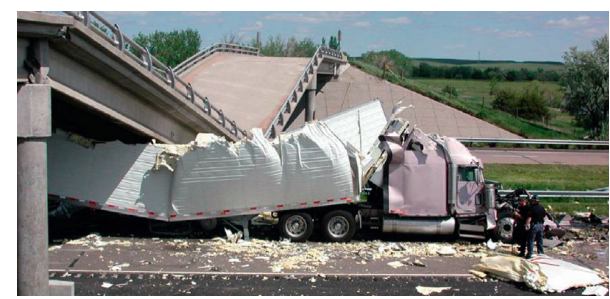

FIGURE 1: Bridge collapse due to a truck hitting a support column in the US state of Nebraska in 2003.

\section{Vehicular Collision Risk Analysis}

In this section, risk analysis using risk-based methodology is described. Firstly, factors for finding the vulnerability and the occurrence of a bridge column under vehicle impact were selected, and then vehicular impact risk analysis was performed with the selected risk factors. Finally, the vulnerability and occurrence of bridge columns under impact were evaluated.

2.1. Risk-Based Methodology. Cremona et al. [2] performed a risk evaluation for precast concrete girders based on riskbased methodology. The risk-based methodology used by Cremona et al. [2] can be classified into three steps. The first step is used to determine levels of disaster, vulnerability, and importance of the structures based on the occurrence and the intensity of disasters. The second step involves Simplified Risk Analysis (SRA), which classifies each group of structures depending on the level of disaster and vulnerability, producing a resulting criticality matrix. Based on the criticality and importance of a structure, the level of risk (low, moderate, or high) for the structure is determined. If the risk level is high, then the third step, Detailed Risk Analysis (DRA), is performed. Numerical analysis for structures in this group was conducted to find their structural vulnerability.

However, if the number of bridge columns runs into the thousands, the classification described above would potentially take too long. Consequently, another methodology was developed that still maintained the basic procedure suggested by Cremona et al. [2]. Korea Expressway Corporation [4] proposed a fire risk analysis of bridges based on the risk-based methodology shown in Figure 2. In the methodology procedure, the first step recommended by Cremona et al. [2] is replaced. We refer to the new step as Preliminary Risk Analysis (PRA). PRA is a classification step that determines the requirement of risk analysis. In the PRA step, structures that do not require risk analysis are screened out and will not be further analyzed. The number of bridge columns in the consideration of risk analysis can be significantly decreased after the first step (PRA), saving considerable time overall. Following PRA, the SRA and DRA steps suggested by Cremona et al. [2] are retained, as shown in Figure 2.

2.2. Determination of Grade Interval. As shown in Figure 2, in the SRA step, structural groups are graded as low, moderate, or high risk based on grade intervals. Therefore, considering grade interval is important for risk analysis. There are many ways to determine the grade interval, as shown in Table 1 [5]. In this study, the standard deviationbased interval (SDI) method was used to determine grade interval according to Min et al. [3] and Lee [5].

In this study, based on the SDI method, each detailed factor was divided into three grades and awarded different points $(1,2$, or 3$)$, as shown in Figure 3 . If the value of the data is lower than the average value $(\mu)$, it is designated as Grade I, and 1 point is given. Likewise, if the value of the data is between the average value $(\mu)$ and $\mu+2 \sigma$, it is designated as Grade II, and 2 points are given. If the value is larger than $\mu+2 \sigma$, it is designated as Grade III, and 3 points are given. If $1 \sigma$ is used as the interval, a large number of Grade III will be assigned. For economical risk analysis for this study, the interval $2 \sigma$ was selected for this study.

2.3. Procedures for Risk Analysis. Each factor for risk analysis is summarized in Table 2. In the PRA step, several factors such as the existence of a bridge column, type of bridge column, and the existence of a lower road, that is, a road passing adjacent to a bridge column, are considered. In this step, if a bridge does not have a column, the bridge column is excluded from the risk analysis. Likewise, if the bridge column is a wall type, it is also excluded from the risk analysis because a wall-type column normally has a wide width, and local failure of the wall due to vehicular impact will not be a critical reason for the collapse of a bridge. Finally, if there is no lower road near a bridge column, it was also excluded from the risk analysis. Accordingly, the number of bridges to be included in the final investigation was significantly diminished, and a more in-depth risk analysis could be undertaken in the SRA and DRA steps.

The collision risk level is calculated by analyzing the factors of occurrence and vulnerability, as shown in Table 2. The specific factors for determining occurrence were types of lower road, existence of a bridge column within $9 \mathrm{~m}$ of the verge of a road, distance from an industrial complex, and truck accessibility to the road. The lower road type could be classified into either a metropolis road, city road, local road, rail road, general highway, or national highway. Truck accessibility means the allowable weight or dimension limits of a truck for each road passing by the bridge column. It is unlikely for a bridge column to collapse under impact from a relatively small vehicle. Most bridge collapses involving vehicles occur because of damage to a bridge column from large vehicles such as cargo trucks [1]. Therefore, cargo trucks were considered in this study.

The points for each detailed factor listed in Table 2 were determined based on SDI method using mean values $(\mu)$ and standard deviation $(\sigma)$, as shown in Figure 3.

According to Korean traffic accident statistics, the number of vehicle accidents within large cities is higher than the number of accidents on intercity highways [6]. Therefore, in this study, for bridge columns with lower roads on a metropolis road or a city road, 3 points were given. For general highways and local roads, 2 points were given. Likewise, for general highways, national highways, and other roads, the lowest point, 1 , was given.

According to design codes, bridge columns under vehicle impact loading must be designed for equivalent static load 


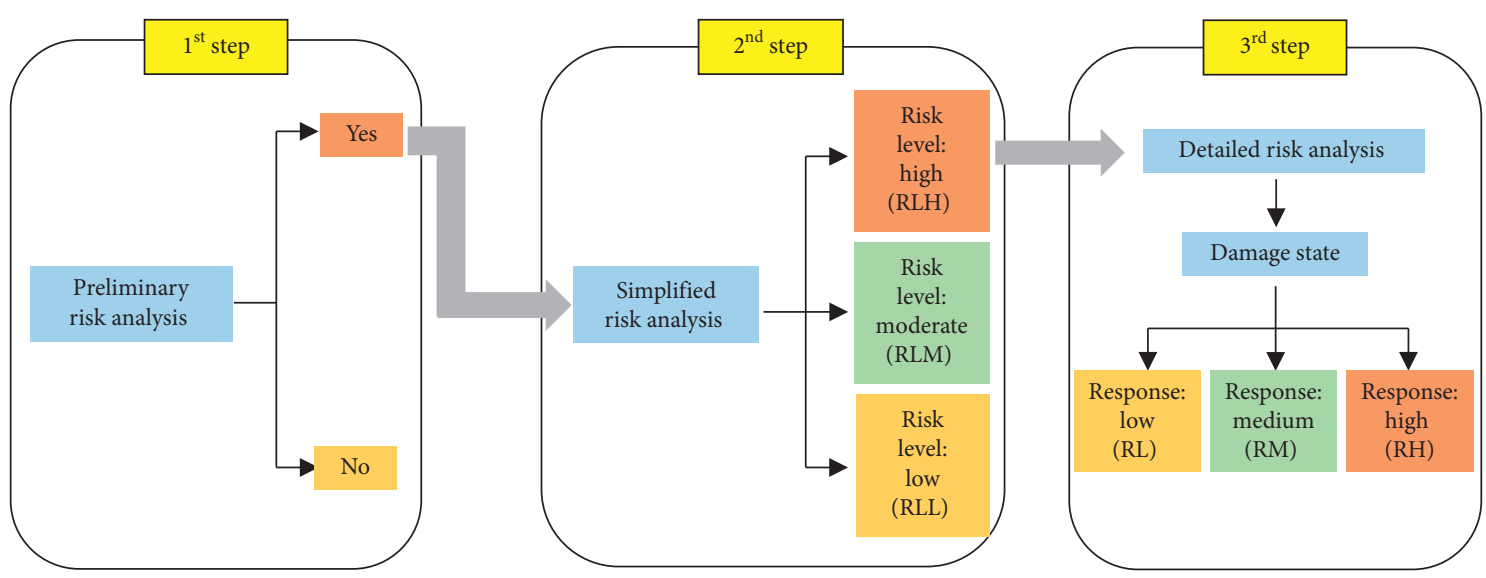

FIGURE 2: Risk-based methodology procedure of this study.

TABLE 1: Various methods for determining grade interval [3].

\begin{tabular}{|c|c|}
\hline Technical data classification & $\begin{array}{c}\text { Natural break } \\
\text { Stepwise correlation } \\
\text { Equal observation } \\
\text { Rank average }\end{array}$ \\
\hline Continuous data classification & $\begin{array}{c}\text { Normal ratio } \\
\text { Standard deviation } \\
\text { Equidistance } \\
\text { Arithmetic progressive scale } \\
\text { Geometrical progressive scale }\end{array}$ \\
\hline
\end{tabular}

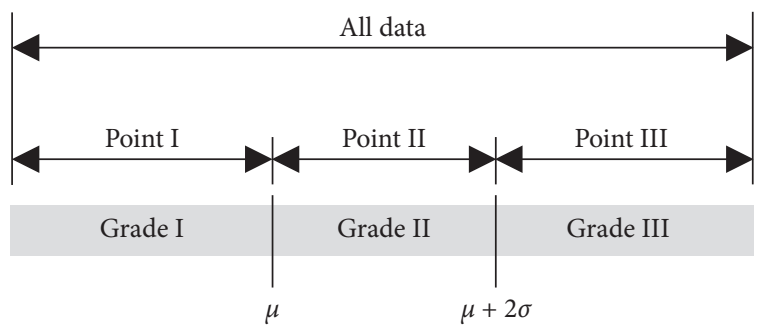

${ }^{*} \mu$ : mean

${ }^{*} \sigma$ : standard deviation

FIGURE 3: SDI method for determining grade interval.

[7-9]. According to the Korea Highway Bridge Design Code (2016), bridge columns located within $9 \mathrm{~m}$ of a road verge must be designed for $1800 \mathrm{kN}$ equivalent static load [8]. Therefore, for bridge columns located within $9 \mathrm{~m}$ of road verges, 3 points were given. For all other cases, 1 point was given. The location of a bridge column from an industrial complex is also an important factor for determining collision occurrence. If the distance from an industrial complex is within $5.77 \mathrm{~km}, 3$ points were given. For distances between $5.77 \mathrm{~km}$ and $95.3 \mathrm{~km}, 2$ points were given. Finally, for distances more than $95.3 \mathrm{~km}, 1$ point was given. These distance limits were determined based on the average distance $(95.3 \mathrm{~km})$ of all the bridge column locations from industrial complexes. The calculated distance values of mean plus 2 sigma, which are shown in Figure 3, using the investigated data of bridges, was $5.77 \mathrm{~km}$.
Points given for truck accessibility to the road were either 1 point or 3 points. When every type of truck on the road is allowed, 3 points were given. Otherwise, 1 point was given.

The detailed factors of vulnerability are also summarized in Table 2. The selected detailed factors were service year, safety level, number of columns, minimum diameter, slenderness ratio, and design load.

Points for the service year of each bridge column were given based on guidelines for safety inspection and precision safety diagnosis (bridge) [10]. A bridge was classified depending on the service year. For bridges aged less than 10 years, 1 point was given. For bridges aged between 10 and 25 years, 2 points were given. For bridges over 25 years, 3 points were given.

Points for the safety level of a bridge column were determined according to the inspection results of each bridge. If the level of safety for a bridge is high (A), the fewest points (1.0) were given. On the other hand, if the bridge safety level is low (D), 3 points were given. For safety level B, 2 points were given.

For the number of bridge columns, 1 point was given if the number of columns is more than 3 , and 2 points were given for column numbers between 2 and 4 . If the number of columns is just 1 , then 3 points were given.

Bridge column diameter might be the most important factor in a vehicle collision. For noncircular cross sections of bridge columns such as ellipse or rectangular types, the minimum diameter (or minimum length for rectangular type) of the bridge column was selected. As illustrated in Figure 3, the mean diameter value was calculated as $1.6 \mathrm{~m}$. If the diameter of a column is larger than $1.6 \mathrm{~m}, 1$ point was given because the diameter can be considered as sufficient. For diameters between $1.2 \mathrm{~m}$ and $1.6 \mathrm{~m}, 2$ points were given. If the bridge column has a diameter less than $1.2 \mathrm{~m}, 3$ points were given. All these grade intervals were determined based on the SDI method shown in Figure 3.

The slenderness ratio is the other factor for determining the grade of vulnerability in the risk analysis procedure. In this study, slenderness ratio was calculated as the height divided by the diameter of the column. The actual slenderness ratio could not be considered in this study since the minimum diameter (or minimum length for rectangular type) of noncircular (ellipse or rectangular types) bridge columns was the only available data. For the details of the 
TABLE 2: Factors for risk analysis.

\begin{tabular}{|c|c|c|c|c|c|}
\hline \multirow{4}{*}{$\begin{array}{l}\text { Types of risk } \\
\text { analysis } \\
\begin{array}{l}\text { Preliminary risk } \\
\text { analysis (PRA) }\end{array}\end{array}$} & \multicolumn{2}{|r|}{ Detailed factors } & \multicolumn{3}{|c|}{ Existence (yes/no) or grade ( 1 to 3 points) } \\
\hline & \multirow{3}{*}{\multicolumn{2}{|c|}{$\begin{array}{c}\text { Existence of bridge column } \\
\text { Type of bridge column } \\
\text { Existence of lower road near bridge }\end{array}$}} & \multirow{3}{*}{\multicolumn{3}{|c|}{$\begin{array}{l}\text { Yes/no } \\
\text { Yes/no } \\
\text { Yes/no }\end{array}$}} \\
\hline & & & & & \\
\hline & & & & & \\
\hline & & & 1 point & 2 points & 3 points \\
\hline \multirow{10}{*}{$\begin{array}{l}\text { Simplified risk } \\
\text { analysis (SRA) }\end{array}$} & \multirow{4}{*}{ Occurrence } & Type of lower road & $\begin{array}{c}\text { National highway, } \\
\text { other road }\end{array}$ & $\begin{array}{c}\text { General highway, local } \\
\text { road }\end{array}$ & $\begin{array}{l}\text { Metropolis road, } \\
\text { city road }\end{array}$ \\
\hline & & $\begin{array}{l}\text { Existence of bridge column } \\
\text { within } 9 \mathrm{~m} \text { of road verge }\end{array}$ & 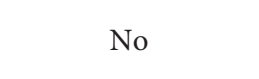 & 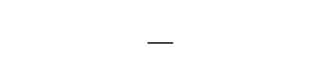 & Yes \\
\hline & & $\begin{array}{l}\text { Distance from industrial complex } \\
\qquad(\mathrm{km})\end{array}$ & $95.30<$ data & $5.77<$ data $<95.30$ & Data $<5.77$ \\
\hline & & $\begin{array}{c}\text { Truck } \\
\text { accessibility to the road }\end{array}$ & No & - & Yes \\
\hline & \multirow{6}{*}{ Vulnerability } & Service year & Data $\leq 10$ & $10<$ data $\leq 25$ & $25<$ data \\
\hline & & Safety level & Level A & Level B & Level D \\
\hline & & Number of columns & $3 \leq$ data & $x=$ data & $x=$ data \\
\hline & & $\begin{array}{l}\text { Minimum diameter of } \\
\text { column }(\mathrm{m})\end{array}$ & $1.6 \leq$ data & $1.2 \leq$ data $<1.6$ & Data $<1.2 \mathrm{~m}$ \\
\hline & & Slenderness ratio & Data $<6$ & $6 \leq$ data $<13$ & $13<$ data \\
\hline & & Design load $(\mathrm{kN})$ & KL-510 (510) & DB-24 (432) & DB-18 (354) \\
\hline
\end{tabular}

slenderness ratio, the mean value $(\mu)$ was 6.0 and standard deviation $(\sigma)$ was 3.5. Accordingly, for bridge columns with a slenderness ratio of less than $6.0,1$ point was given. For columns with slenderness ratios between 6.0 and 13.0, 2 points were given. Finally, for columns with a slenderness ratio of more than 13,3 points were given.

For determining the grade interval of the design load, Korea Highway Bridge Design Code $[7,8]$ was referred to instead of using SDI methods. If the considered truck load is $510 \mathrm{kN}$ (KL-510), 1 point was given. If the truck load is DB$24(432 \mathrm{kN}), 2$ points were given, and if the truck load is DB$18(324 \mathrm{kN})$ or under, 3 points were given.

Table 3 shows one example of the SRA in the procedure of risk analysis in this study. All detailed points for occurrence and vulnerability were summed up separately. Then these sums of occurrence and vulnerability were normalized by maximum points of each detailed factor. Final risk levels such as Risk Level High (RLH), Risk Level Moderate (RLM), and Risk Level Low (RLL) are determined by summing both normalized occurrence and vulnerability values, as shown in the far right column of Table 3. The classification criteria for RLL, RLM, and RLH use the average $(\mu)$ and standard deviation $(2 \sigma)$, as shown in Figure 3.

For this study, 0.5 weight factors were applied for both normalized occurrence and vulnerability values in order to minimize any subjective judgements. Therefore, determination of each weight factor for both occurrence and vulnerability should be considered as the future work.

2.4. Results from Preliminary Risk Analysis (PRA). Results of PRA are shown in Figure 4. As previously explained, PRA is a screening step, and this step judges the requirement of risk analysis before any further analysis. Therefore, the details of factors such as the existence of a bridge column, type of bridge column, and existence of a lower road near a bridge column, as shown in Table 2, are confirmed in this step. For example, wall-type structures were screened out, and bridge columns with no lower roads were also screened out because there is a very low chance of bridge collapse in those cases. These bridge columns were categorized in the "No Risk" group. However, if a bridge column was not screened out in the PRA step, the bridge column was categorized in the "Risk" group.

The number of "No Risk" bridge columns was 6,286 (74.6\%) while the number of bridge columns in the "Risk" category was $1,944(23.1 \%)$ as shown in Figure 4 . For the purpose of our risk analysis, data of 195 bridge columns were inadequate. This is $2.3 \%$ of the total number of bridge columns. Therefore, 1,944 bridge columns were selected in this study for the SRA step.

2.5. Results of Simplified Risk Analysis (SRA). SRA was conducted after the PRA screening step. As previously explained, using the detailed factors of SRA, points of both occurrence and vulnerability were chosen, and the risk levels of both occurrence and vulnerability were normalized and determined, respectively. If the normalized point was larger than 0.75 , it was considered RLH. If the normalized point was less than 0.65 , it was considered RLL. For bridge columns categorized between these two levels, they were considered RLM. The value of 0.65 was the obtained mean value $(\mu)$ from the available data, and the value of 0.75 was the mean value $(\mu)$ plus standard deviation $(2 \sigma)$.

Accordingly, using SRA, the obtained number of bridge columns in the RLM category in the factor of occurrence was 1,376 , as shown in Figure 5. This represents $70.8 \%$ of the total number of columns $(1,944)$. This indicates that most bridge columns are in the category of RLM in the factor of occurrence. The RLL was $3.8 \%$ and RLH was $18.3 \%$. In South Korea, many bridge columns are located near the verge of lower roads, and the number of bridge columns having truck accessibility regulations is low. Consequently, a small portion of bridge columns was categorized as RLL, and a 


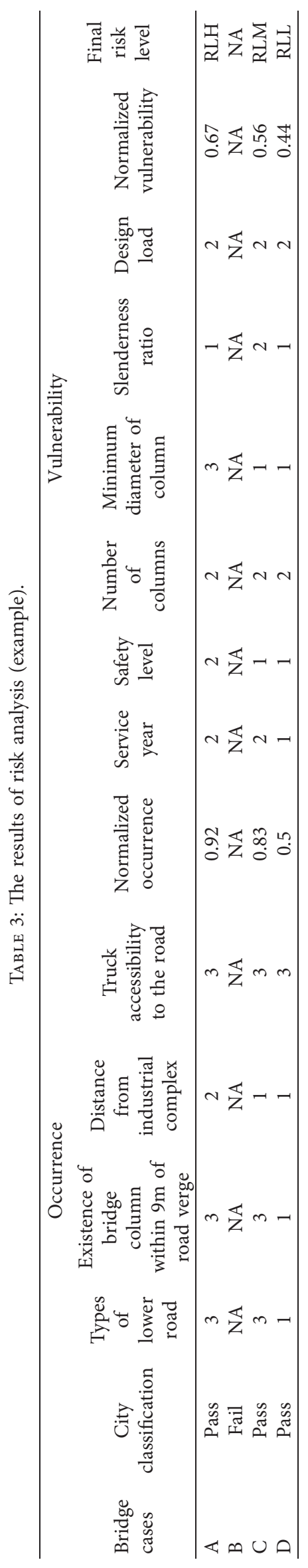




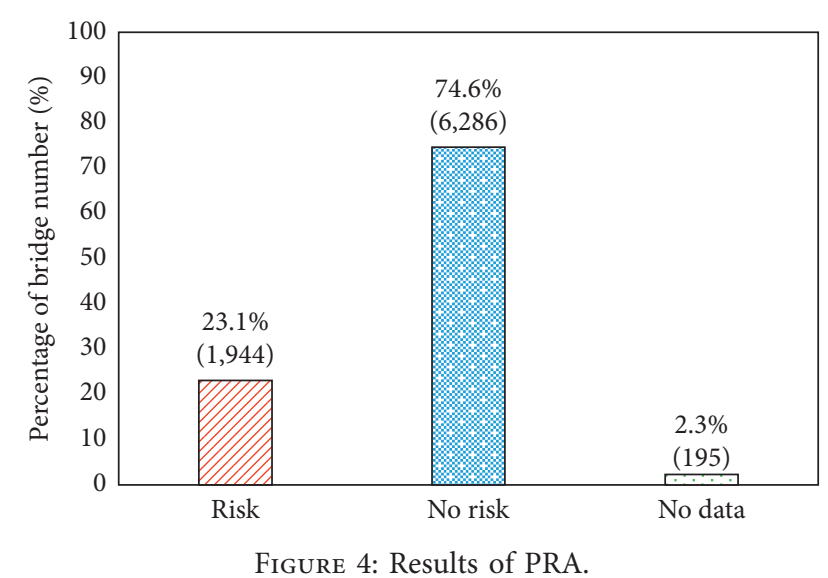

FIgURe 4: Results of PRA.

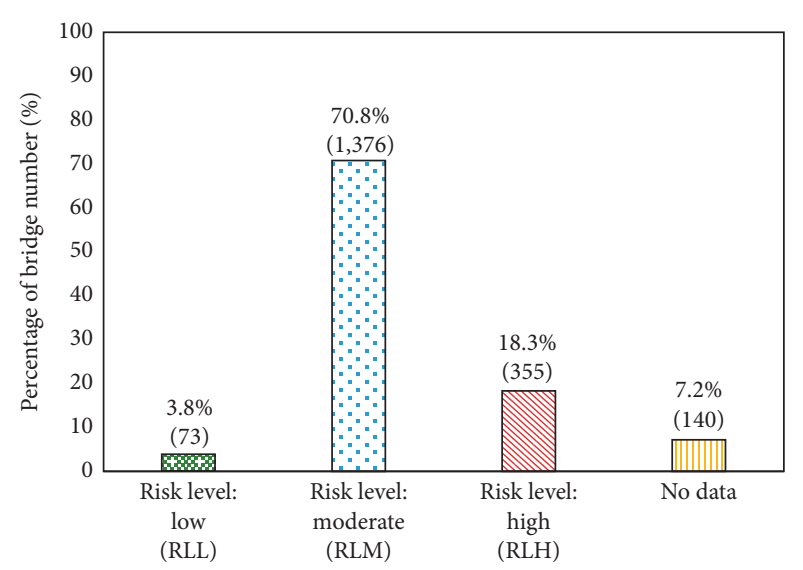

Figure 5: Results of occurrence.

relatively larger portion of the bridge columns was categorized as RLM or RLH.

The obtained results of vulnerability in SRA are shown in Figure 6. Of note is that, contrary to the results of occurrence, most bridge columns in South Korea are categorized as RLL or RLM. The number of bridge columns in the RLH category was only $2.0 \%$. This indicates that bridge design in South Korea has an adequate safety margin, and added to that, most bridge ages are relatively younger compared with other countries with advanced highway infrastructure such as Japan or the United States.

For the risk analysis of bridge columns specifically located in South Korea, consideration of both occurrence and vulnerability is therefore an important step for finalizing the risk level. Furthermore, the determination of weight factors for both occurrence and vulnerability would be key procedures for finding the final risk level of each bridge column.

The final results of SRA after consideration of both occurrence and vulnerability are shown in Figure 7. The results obtained after consideration of both occurrence and vulnerability showed that most bridge columns fall into the RLL (42.9\%) or RLM (34.6\%) categories. Bridge columns categorized as RLH (2.7\%) in the SRA were only considered in the DRA. This resulted in an eventual 58 bridge columns

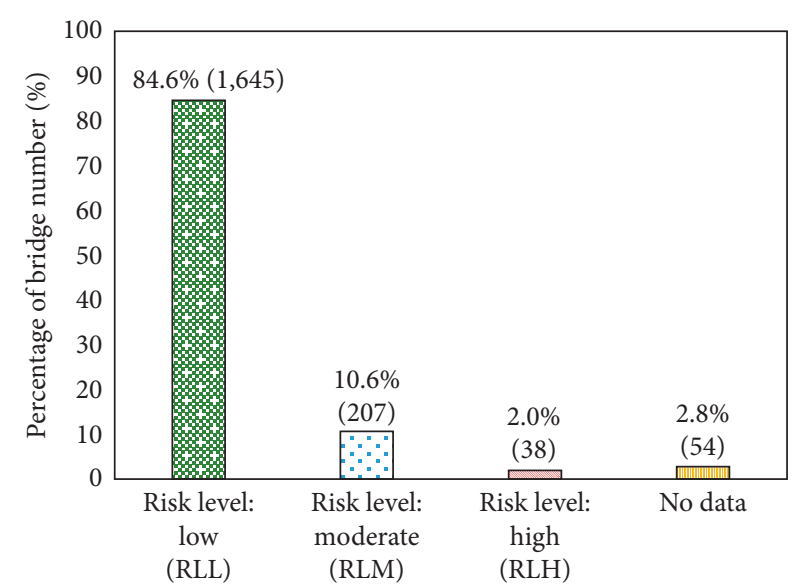

Figure 6: Results of vulnerability.

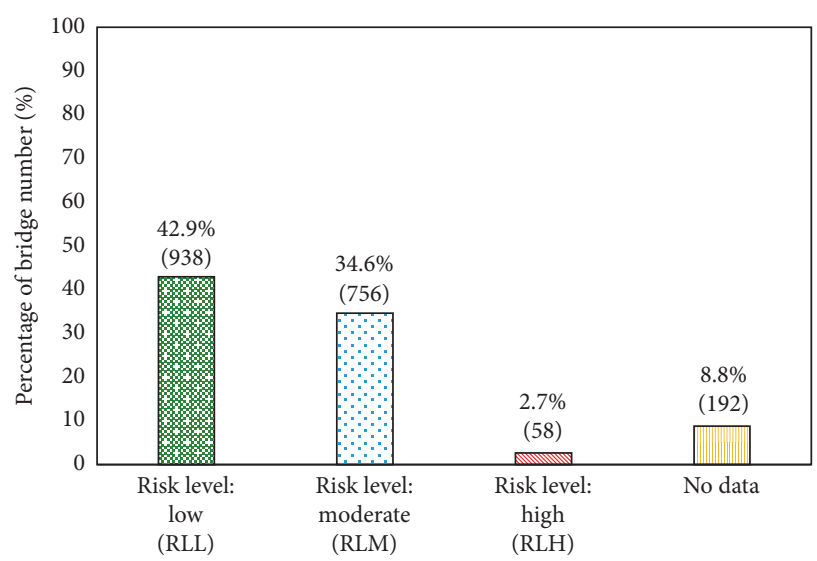

FIgURE 7: Final results of SRA.

only being selected for DRA, and this is only $0.7 \%$ of the total number of investigated bridge columns. Therefore, based on our conducted method for bridge column risk analysis, it can be concluded that bridge columns in South Korea could be considered to be safe under heavy vehicle impact.

\section{Numerical Analysis}

For the DRA, numerical analysis was conducted to find the angle of rotation of bridge columns following heavy vehicle impact. Among 58 bridge columns, which were categorized as RLH in the SRA, five types of bridge column depending on the slenderness ratio were grouped, and numerical analysis was conducted for each type of bridge column.

3.1. Numerical Model Development. The selected vehicle model in this study was a 38-ton cargo truck with trailer, taken from publicly available models listed by the National Crash Analysis Center (NCAC), as shown in Figure 8. This vehicle model has standard dimensions according to European Standard EN-1317, with a length of $16 \mathrm{~m}$, a height of 


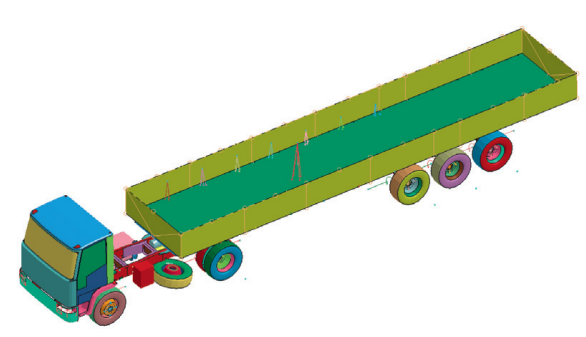

Figure 8: Truck model (National Crash Analysis Center).

$2.8 \mathrm{~m}$, and a width of $2.5 \mathrm{~m}$. This vehicle is composed of beam elements, shell elements, solid elements, and mass elements. Furthermore, different materials are considered in this truck model, including steel and rubber.

Lee et al. [11] conducted numerical analysis of a concrete median barrier and a heavy vehicle. In that study, a key parameter was varied. The curb weight was changed, while the total weight of each case was kept unchanged. The results obtained from the study indicated that the impact loadings on the concrete median barrier were severely changed depending on the different vehicle curb weight. Therefore, it should be noted that simulation results could vary depending on the different curb weight of a vehicle. In our study, a 38-ton cargo truck has a curb weight of 14.1 tons according to EN-1317 [12].

The commercially available program LS-DYNA was used for the impact analysis of a bridge column and a 38-ton truck. Solid elements of the concrete column were modeled by a constant-stress, one-point quadrature integration to reduce the computational time. The selected material model for the concrete was the Continuous Surface Cap Model (CSCM), which was developed for roadside safety applications by the United States Federal Highway Administration. The CSCM model offers several capacities, such as strength degradation, stiffness degradation, multiaxial strength, strain rate effects, and erosion. Detailed information for CSCM can be found in Murray [13] and Murray et al. [14]. One of the key parameters in CSCN is "erode." This value determines the removal of the damaged elements due to collision. The elements are eroded when the plastic strain exceeds this value, thus changing the contact surface after element erosion during the analysis. The value of 1.4 was selected for the erode parameter according to El-Tawil et al. [15]. Another important key parameter is the fracture energy of concrete. Concrete fracture energy can control the performance of a bridge column, such as through influencing crack formation, crack propagation, and element erosion. The best way to select the fracture energy is through measuring by experimental testing. However, the fracture energy can also be estimated using the FIP Code Model [16]:

$$
\begin{aligned}
f_{\mathrm{ctm}} & =0.3\left(f_{\mathrm{ck}}\right)^{2 / 3}, \\
G_{\mathrm{f}} & =73 f_{\mathrm{cm}}^{0.18},
\end{aligned}
$$

where $f_{\mathrm{ctm}}$ is the tensile strength, $f_{\mathrm{ck}}$ is the characteristic compressive strength, $G_{\mathrm{f}}$ is the fracture energy of concrete, and $f_{\mathrm{m}}$ is the mean compressive strength at the age of 28 days.
For the steel material model, Piecewise Linear Plasticity was selected. To estimate the strain rate effect, the Cowper-Symonds equation was used in this material model:

$$
\sigma_{\mathrm{rr}}^{F}\left(\dot{\varepsilon}^{p}\right)=\sigma_{\mathrm{rr}}^{F\left[1+\left(\frac{\dot{\varepsilon}}{C}\right)^{(1 / p)}\right]},
$$

where $\sigma_{\mathrm{rr}}^{F}$ is the static failure stresses, $\dot{\mathcal{\varepsilon}}^{p}$ is the average plastic strain rate, and $C, p$ is the coefficient for strain rate.

In this study, the selected $C$ and $p$ coefficients were $1.05 E+7 \mathrm{~s}^{-1}$ and 8.3, referring to Chung et al. [17]. Steel rebar was embedded within the concrete as Lagrange in Solid option. The details of Piecewise Linear Plasticity model and Lagrange in Solid option can be found in the LS-DYNA user manual [18].

Determination of the boundary condition is an important step for modeling a bridge column. Kim et al. $[19,20]$ performed numerical analysis of bridge column vehicle impact depending on different boundary conditions of the bridge column. It was found that the boundary condition shown in Figure 9 (the top was restrained in only the impact loading direction and the bottom was fixed) showed the largest deformation compared with other cases. For simplicity and conservative results, we used this boundary condition for the numerical analysis of all types of bridge column. A more detailed discussion of boundary conditions of bridge columns under vehicle impact loadings can be found in Kim et al. [19, 20].

The total of 58 bridge columns in the RLH category following SRA can be further classified into five types based on their slenderness ratio, as shown in Table 4. Each column had a circular cross section with a $1,112 \mathrm{~mm}$ diameter based on the average value of the bridge column obtained from the RLH category. However, different lengths of bridge column were applied to the numerical analysis depending on the slenderness ratio, as shown in Table 4 . The columns with a slenderness ratio below $3(\mu-\sigma)$ are column type I. If the slenderness ratio was between $3(\mu-\sigma)$ and $6(\mu)$, they are column type II. For column with a slenderness ratio between $6(\mu)$ and $9(\mu+\sigma)$, they are column type III. Column types $\mathrm{IV}$ and $\mathrm{V}$ were also assigned. Each column type and corresponding slenderness ratios are summarized in Table 4. It was assumed that the reinforcement ratio is $1.3 \%$ for all types of columns because the value was selected from the typical columns situated along the Gyeongbu Expressway in South Korea.

Numerical analysis was conducted as the speed of the cargo truck was increased in increments of $10 \mathrm{~km} / \mathrm{h}$, from $100 \mathrm{~km} / \mathrm{h}$ to $130 \mathrm{~km} / \mathrm{h}$. Deformation of the bridge column was obtained at the rear side of the impacted area from the conducted numerical analysis. The damage level was determined based on response limits according to Design of Blast-resistant Buildings in Petrochemical Facilities [21]. This reference design code suggests the damage level of a building depends on the support rotation, as shown in Table 5. In the design code, low response is defined as a localized component damage, meaning a damaged structure can be used while repairs are being carried out. Concrete structures of moderate response should not be occupied until repair. Concrete structures of high response should not 


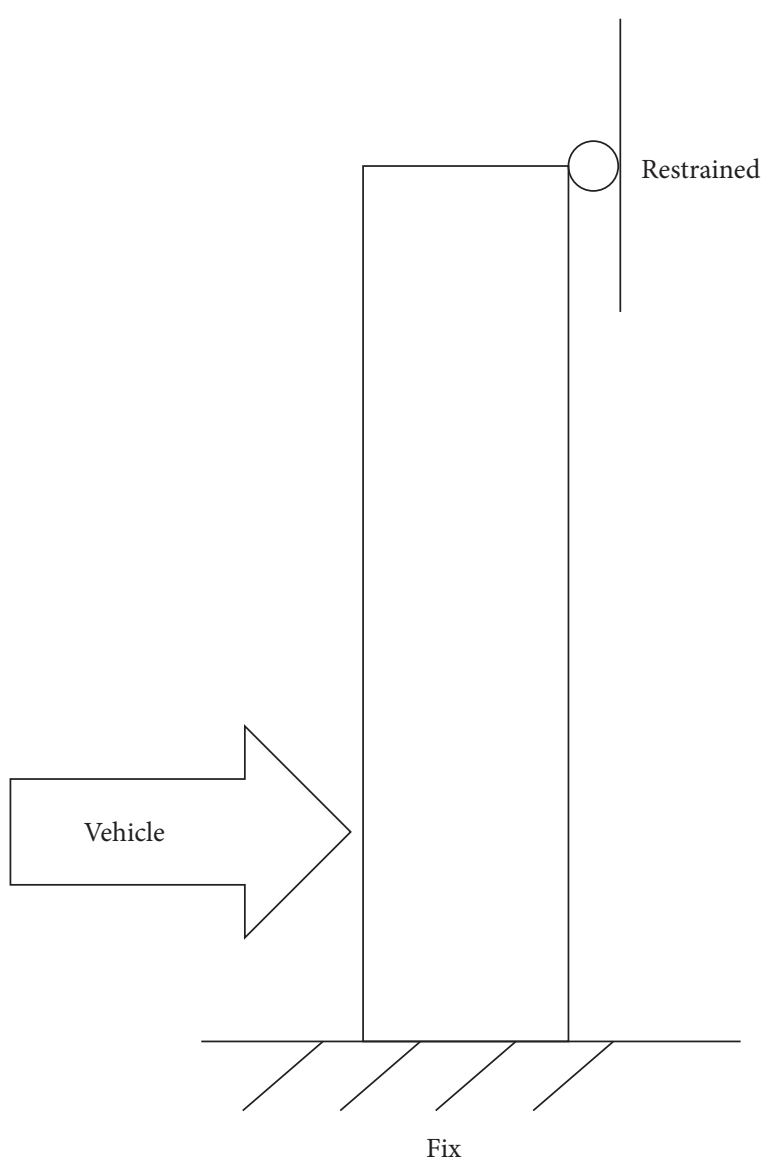

FIGURE 9: Boundary conditions of bridge column.

TABle 4: Column types based on slenderness ratio.

\begin{tabular}{lcccc}
\hline Type & $\begin{array}{c}\text { Average } \\
\text { length } \\
(\mathrm{mm})\end{array}$ & $\begin{array}{c}\text { Average } \\
\text { diameter } \\
(\mathrm{mm})\end{array}$ & $\begin{array}{c}\text { Range of } \\
\text { slenderness } \\
\text { ratio }\end{array}$ & $\begin{array}{c}\text { Average } \\
\text { slenderness } \\
\text { ratio }\end{array}$ \\
\hline $\begin{array}{l}\text { Column } \\
\text { type I }\end{array}$ & 2,112 & 1,112 & Data $\leq 3$ & 1.9 \\
$\begin{array}{l}\text { Column } \\
\text { type II }\end{array}$ & 4,474 & 1,112 & $3 \leq$ data $\leq 6$ & 4.0 \\
$\begin{array}{l}\text { Column } \\
\text { type III }\end{array}$ & 6,890 & 1,112 & $6 \leq$ data $\leq 9$ & 6.2 \\
$\begin{array}{l}\text { Column } \\
\text { type IV } \\
\text { Column } \\
\text { type V }\end{array}$ & 11,056 & 1,112 & $9 \leq$ data $\leq 13$ & 9.9 \\
\hline
\end{tabular}

be occupied due to collapse. Based on these response labels, the damage of a concrete bridge column under vehicle collision was evaluated in our study.

3.2. Numerical Analysis Results. Table 6 and Figure 10 show the deformation and support rotational degree of bridge columns depending on impact speed. The support rotation of column type I was less than $4^{\circ}$ until the impact speed increased up to $120 \mathrm{~km} / \mathrm{h}$. Therefore, the results of column type I show that it is not vulnerable under a 38-ton truck
TABLE 5: Response limits for reinforced concrete.

\begin{tabular}{lccc}
\hline $\begin{array}{l}\text { Element } \\
\text { type }\end{array}$ & \multicolumn{3}{c}{ Support rotation $\theta\left(^{\circ}\right)$} \\
\hline $\begin{array}{l}\text { Beam- } \\
\text { columns }\end{array}$ & Response low & Response & Response high \\
& $(\mathrm{RL})$ & moderate (RM) & $(\mathrm{RH})$ \\
& 1 & 2 & 4 \\
\hline
\end{tabular}

TABle 6: Deformation of bridge column depending on impact speed.

\begin{tabular}{lccccc}
\hline $\begin{array}{l}\text { Truck } \\
\text { speed } \\
(\mathrm{km} / \mathrm{h})\end{array}$ & $\begin{array}{c}\text { Column } \\
\text { type I } \\
(\mathrm{mm})\end{array}$ & $\begin{array}{c}\text { Column } \\
\text { type II } \\
(\mathrm{mm})\end{array}$ & $\begin{array}{c}\text { Column } \\
\text { type III } \\
(\mathrm{mm})\end{array}$ & $\begin{array}{c}\text { Column } \\
\text { type IV } \\
(\mathrm{mm})\end{array}$ & $\begin{array}{c}\text { Column } \\
\text { type V } \\
(\mathrm{mm})\end{array}$ \\
\hline 100 & 10.3 & 22.9 & 14.2 & 17.1 & 16.9 \\
110 & 23.3 & 33.9 & 36.2 & 38 & 35.0 \\
120 & 43.3 & 66.3 & 68.0 & 96.6 & 119 \\
130 & 49.7 & 118 & 110 & 204 & 222 \\
\hline
\end{tabular}

collision until $120 \mathrm{~km} / \mathrm{h}$. However, other column types showed larger support rotation than column type I as the slenderness ratio increased. There was no significant variation among the support rotations from column types II to $\mathrm{V}$ until $110 \mathrm{~km} / \mathrm{h}$. It was confirmed that there were two main effects. First, the shear resistance capacity of a bridge column was the same because of the same bridge column diameter. Second, the same fixed boundary condition also affected the deformation because the collision area was close to the lower end of the bridge column. Therefore, no significant variation among the support rotations was evidenced.

However, it is reckoned that because column type I has a relatively smaller slenderness ratio and the top part of the column is restrained in the loading direction, a smaller support rotation from column type I was obtained.

As an example, the shape of a truck and the type IV bridge column after a vehicle collision are shown in Figures 11 and 12. The truck bumper first struck the column and then the cargo part hit the column next, affecting the increment of the impact loading on the column. The maximum deformation of the column occurred at the impact area of the bumper. The maximum deformation of the truck occurred at the central front area, and the driver's seat was completely deformed (Figure 11). As expected, the deformation of the bridge column showed a larger deformation while the vehicle impact speed increased. The shear failure was concentrated in a section of the impacted area due to the large concentrated deformation. The failure area of the bridge column also increased while the truck speed increased (Figure 12). The largest deformation and failure area were observed at an impact location, as expected.

The flexural failure of the column at the rear side of the impact area was also observed in all columns, as shown in Figure 12. The amount of flexural damage increased with increasing impact speed.

The impact force-time history graphs of column type IV are shown in Figure 13. The maximum loading from a 38-ton truck with a speed of $130 \mathrm{~km} / \mathrm{h}$ was recorded as $6210 \mathrm{kN}$. In other cases, the peak loads were $5786 \mathrm{kN}, 5303 \mathrm{kN}$, and 


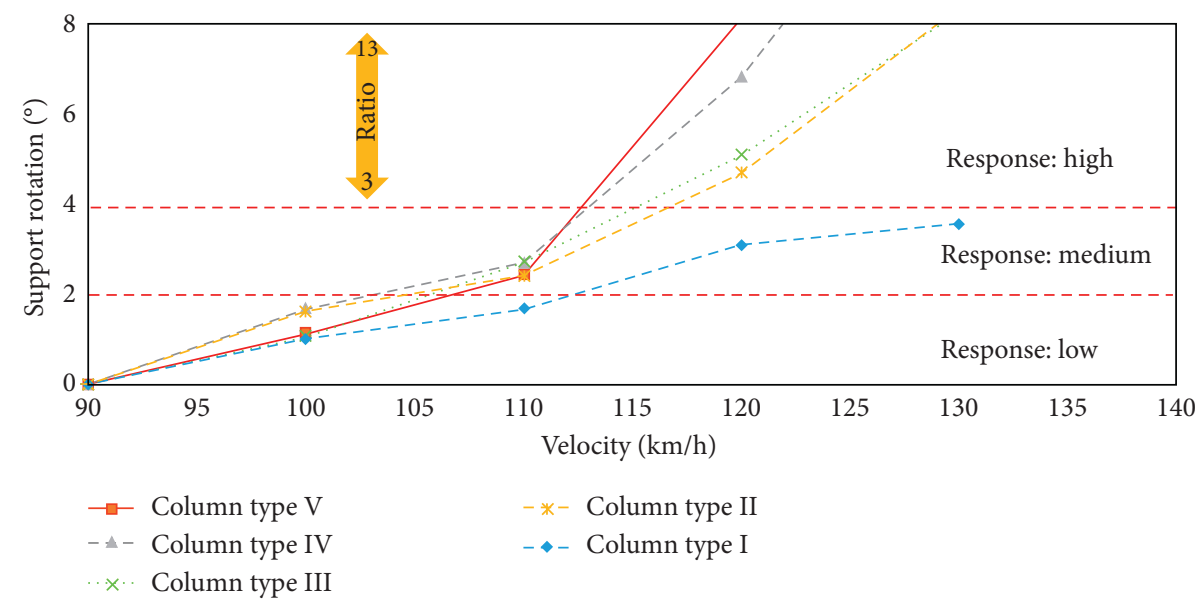

FIGURE 10: Support rotation degree of the bridge column depending on impact speed.

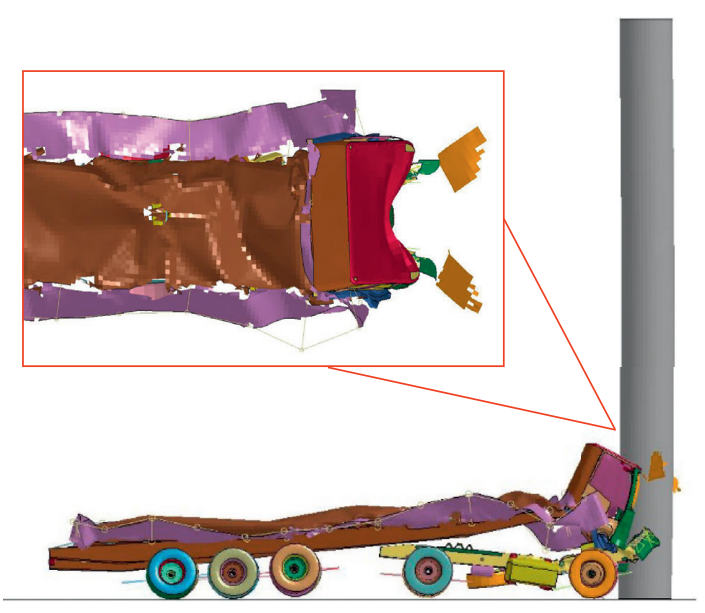

(a)

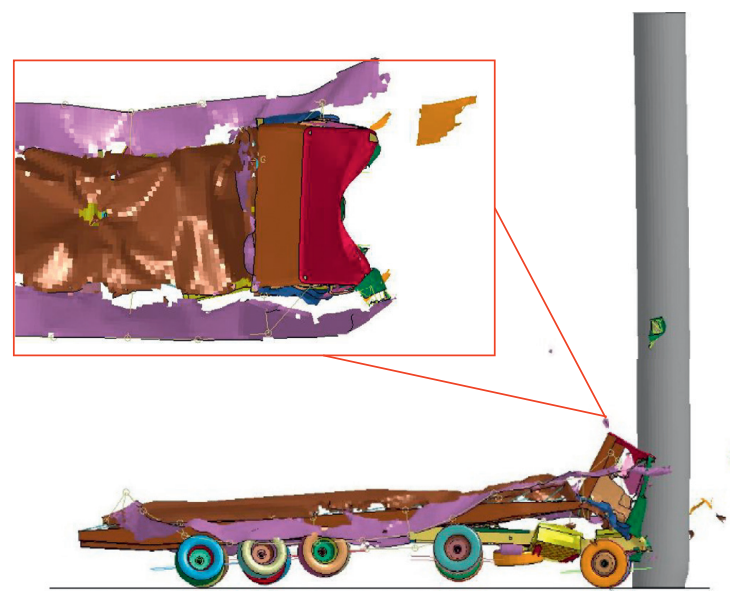

(c)

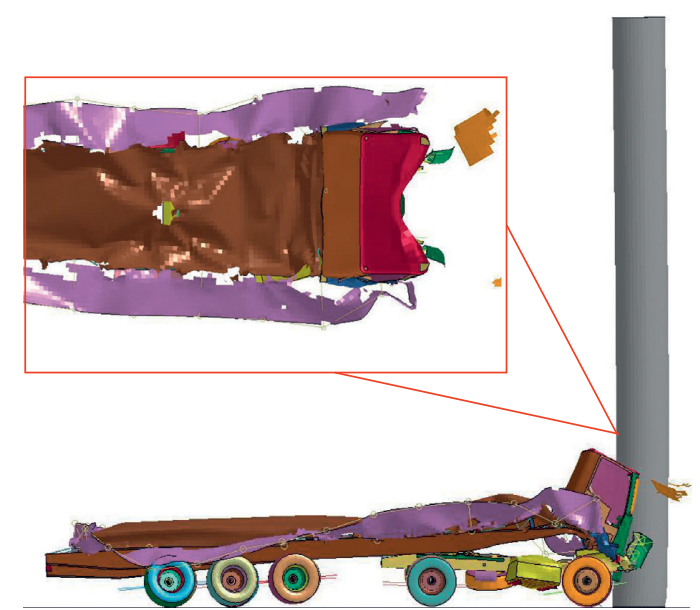

(b)

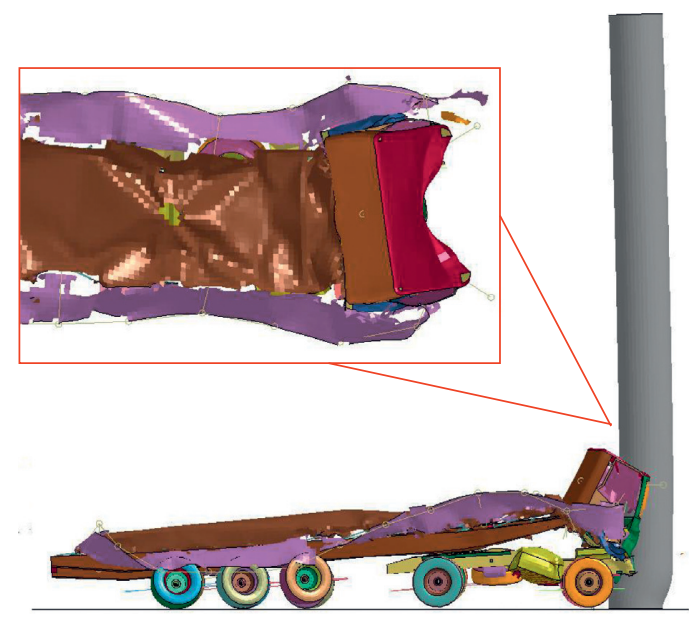

(d)

FIGURE 11: Shape of truck and bridge column depending on impact speed (column type IV). (a) $100 \mathrm{~km} / \mathrm{h}$. (b) $110 \mathrm{~km} / \mathrm{h}$. (c) $120 \mathrm{~km} / \mathrm{h}$. (d) $130 \mathrm{~km} / \mathrm{h}$.

$4769 \mathrm{kN}$ from $120 \mathrm{~km} / \mathrm{h}, 110 \mathrm{~km} / \mathrm{h}$, and $100 \mathrm{~km} / \mathrm{h}$, respectively. The maximum load increased by $11.2 \%, 9.1 \%$, and $7.4 \%$ while the impact speed increased by $10 \mathrm{~km} / \mathrm{h}$, meaning the largest load increased when the collision speed increased from $100 \mathrm{~km} / \mathrm{h}$ to $110 \mathrm{~km} / \mathrm{h}$. The second largest loads were observed due to the impact of the cargo. 


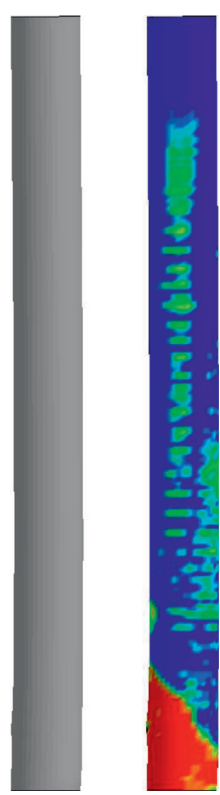

(a)

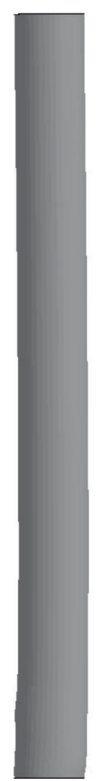

(b)

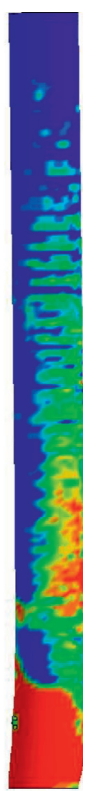

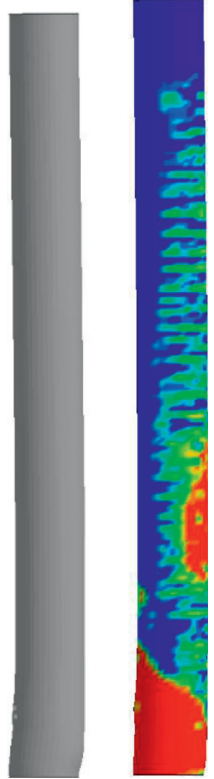

(c)

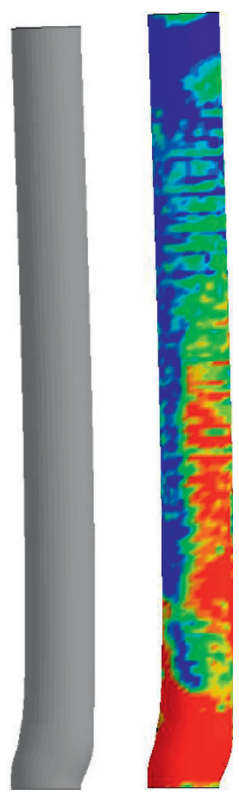

(d)

FIGURE 12: Shape of bridge column after vehicle collision (column type IV)). (a) $100 \mathrm{~km} / \mathrm{h}$. (b) $110 \mathrm{~km} / \mathrm{h}$. (c) $120 \mathrm{~km} / \mathrm{h}$. (d) $130 \mathrm{~km} / \mathrm{h}$.

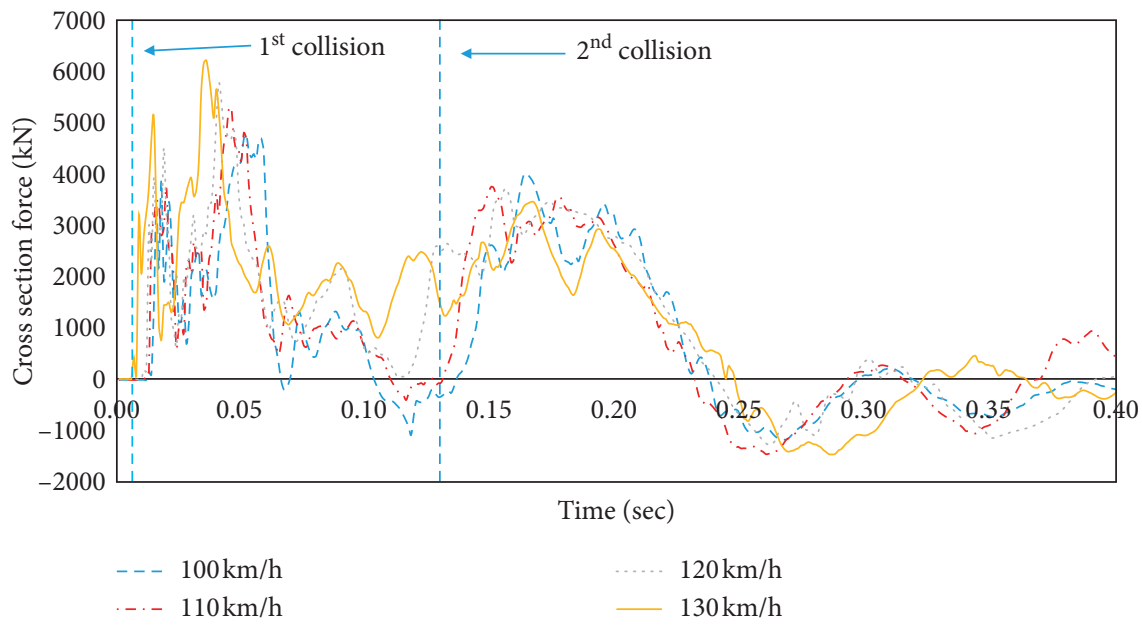

Figure 13: Load-time history graph of the bridge column (column type IV).

Deformations at the rear side of the impacted area are also shown in Figure 14. Large deformation was observed from $130 \mathrm{~km} / \mathrm{h}$. The maximum cross section force of the bridge column was observed in the first collision, which reflects the impact of bumper; however, the maximum deformation was observed in the second collision due to the impact of the cargo, which had several mass elements. In the first collision, the impact energy was absorbed by the large deformation of the truck front and the bumper in the first collision. If the bumper is stiffer than this, a larger cross-sectional force could be obtained. In the second collision, the column deformation was larger than the deformation in the first collision, and we can observe that the second collision showed a longer plateau force of about $3000 \mathrm{kN}$. Based on this observation, it is thought that the larger deformation is related to the level of force and the time duration of the relatively high plateau force.
In order to confirm the vulnerability of bridge columns under impact of a truck, a parametric study was conducted with material properties such as steel rebar yield strength and concrete compressive strength using the developed model. Finally, fragility curves of bridge columns under vehicle impact are presented based on the obtained results.

A fragility curve defines the probability of exceeding a predefined performance state at varying levels of earthquake intensity. Shinozuka et al. [22, 23] used the maximum likelihood method to generate empirical fragility curves from observations of bridge damage in an earthquake. The likelihood function for the present purpose is

$$
L=\prod_{i=1}^{N}\left[F\left(a_{i}\right)\right]^{x_{i}}\left[1-F\left(a_{i}\right)\right]^{1-x_{i}}
$$




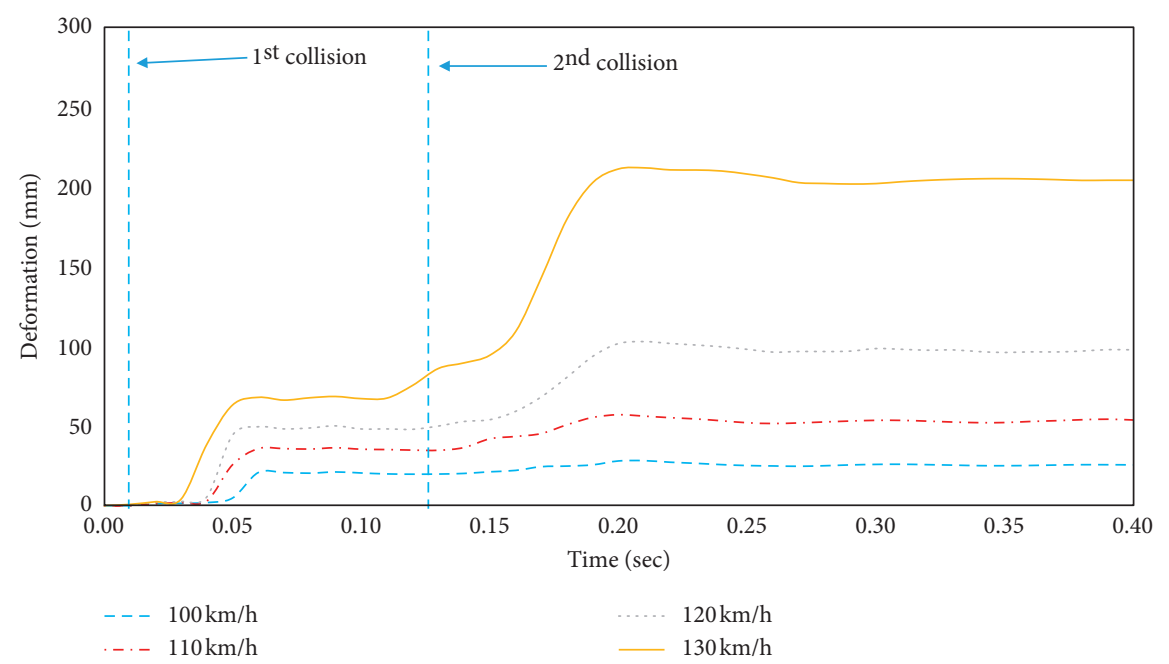

FIgURE 14: Deformation-time history graph at the rear side of the impacted area (column type IV).

where $F($ ) represents the fragility curve for a state of damage, $a_{i}$ is the impact speed in this study, $N$ is total number of bridge columns in this study after collision, and $x_{i}$ is 1 or 0 depending on whether or not the bridge column collapses under impact conditions. $F(a)$ is

$$
F(a)=\Phi\left[\frac{\ln (a / c)}{\zeta}\right] .
$$

In this study, " $a_{i}$ " represents impact speed and $[\Phi]$ is the standardized normal distribution function. Parameters such as $c$ and $\zeta$ are computed to satisfy the following equations to maximize $\ln L$ :

$$
\frac{\mathrm{d} \ln L}{\mathrm{~d} c}=\frac{\mathrm{d} \ln L}{\mathrm{~d} \zeta}=0 .
$$

In this study, the key parameters selected for the fragility curve were concrete compressive strength and yield strength of steel rebar. Gardoni et al. [24] suggested the standard deviation of concrete compressive strength $(2.76 \mathrm{MPa})$ and steel rebar yield strength $(22.4 \mathrm{MPa})$. Based on suggested data [24], a normal distribution curve was generated using the mean value (concrete compressive strength: $30 \mathrm{MPa}$; steel rebar yield strength: $520 \mathrm{MPa}$ ) and standard deviation (concrete: $2.76 \mathrm{MPa}$; steel rebar: $22.4 \mathrm{MPa}$ ). The virtual data were then generated using a normal distribution curve. To note, the generated data points may lie outside of the physically possible range, in which a $y$-axis value of less than 1 was eliminated for presenting fragility curves. Then, the $x$ axis represents truck speed and the $y$-axis represents the results of analysis data points. For this study, it was found that deformations were sensitive between $110 \mathrm{~km} / \mathrm{h}$ and $120 \mathrm{~km} / \mathrm{h}$. Therefore, additional analysis for $115 \mathrm{~km} / \mathrm{h}$ was conducted to observe deformation in detail.

Numerical analysis was conducted with concrete compressive strength such as $26 \mathrm{MPa}, 30 \mathrm{MPa}$, and $34 \mathrm{MPa}$ and steel rebar yield strength such as $470 \mathrm{MPa}, 520 \mathrm{MPa}$, and $570 \mathrm{MPa}$. Since the number of numerical analyses is limited and it is hard to manipulate data, results obtained (rotational degree) from numerical analysis were used for interpolation between two points in order to find the rotational degree if the numerical analysis was not conducted.

The next step was to combine these two groups of data points, which are the generated number of virtual data and the results of numerical model as combinations. For example, with the impact condition of $110 \mathrm{~km} / \mathrm{h}$ and column type $\mathrm{V}$ with $30 \mathrm{MPa}$ concrete, a 2.4 rotational degree was obtained from numerical analysis. Since a rotational degree of 2.4 is less than a rotational degree of 4.0 , which is the response limit for $\mathrm{RH}$, this demonstrates success. From the normal distribution of the concrete strength, $30 \mathrm{MPa}$ is the mean value in this study, and it represents $14 \%$ of total cases. Therefore, in this case, $14 \%$ of total cases could be considered to be successful.

In order to check the determination of the success/ failure status, as previously mentioned, response limits were used, which are shown in Table 5. In determination of the success/failure, "0" stands for success, which is below response limits, and " 1 " stands for failure, which is above response limits. A more detailed discussion for the method of generating the virtual data can be found in Kim et al. $[25,26]$. Finally, to calculate the probability of each point, the cumulative log normal distribution method was used. Based on this procedure, fragility curves from normal distributions of concrete strength and steel yielding strength were found.

The median and corresponding dispersion (standard deviation) values for each bridge column type are summarized in Table 7. As expected, the larger deformations were obtained if the slenderness ratio of the selected bridge column was increased. For the response high (RH) response limit, the median value from $111.7 \mathrm{~km} / \mathrm{h}$ to $135.0 \mathrm{~km} / \mathrm{h}$ was obtained when the statistical distribution of concrete compressive strength was considered. And the standard deviation value was obtained from $0.10 \mathrm{~km} / \mathrm{h}$ to $0.16 \mathrm{~km} / \mathrm{h}$. The median value from $112.7 \mathrm{~km} / \mathrm{h}$ to $132.3 \mathrm{~km} / \mathrm{h}$ was obtained and the standard deviation value from $0.08 \mathrm{~km} / \mathrm{h}$ to $0.10 \mathrm{~km} / \mathrm{h}$ was obtained when the statistical distribution of steel rebar yield strength was considered. For the response moderate (RM) response limit, the median value from $104.3 \mathrm{~km} / \mathrm{h}$ to $112.4 \mathrm{~km} / \mathrm{h}$ and $105.3 \mathrm{~km} / \mathrm{h}$ to $113.8 \mathrm{~km} / \mathrm{h}$ was obtained and 
TABLE 7: Median values and standard deviation values depending on column types.

\begin{tabular}{|c|c|c|c|c|c|c|c|}
\hline Statistical distribution & Response & Value types & $\begin{array}{c}\text { Column type } \\
\text { I }\end{array}$ & $\begin{array}{l}\text { Column type } \\
\text { II }\end{array}$ & $\begin{array}{l}\text { Column type } \\
\text { III }\end{array}$ & $\begin{array}{l}\text { Column type } \\
\text { IV }\end{array}$ & $\begin{array}{c}\text { Column type } \\
\text { V }\end{array}$ \\
\hline \multirow{4}{*}{$\begin{array}{l}\text { Concrete compressive } \\
\text { strength }\end{array}$} & \multirow[b]{2}{*}{$\mathrm{RH}$} & Median $(\mathrm{km} / \mathrm{h})$ & 135.0 & 119.8 & 115.4 & 113.6 & 111.7 \\
\hline & & $\begin{array}{l}\text { Standard deviation } \\
\qquad(\mathrm{km} / \mathrm{h})\end{array}$ & 0.10 & 0.12 & 0.16 & 0.12 & 0.15 \\
\hline & \multirow[b]{2}{*}{ RM } & Median $(\mathrm{km} / \mathrm{h})$ & 112.4 & 107.2 & 106.8 & 105.9 & 104.3 \\
\hline & & $\begin{array}{l}\text { Standard deviation } \\
(\mathrm{km} / \mathrm{h})\end{array}$ & 0.10 & 0.13 & 0.13 & 0.15 & 0.12 \\
\hline \multirow{4}{*}{ Steel rebar yield strength } & \multirow[b]{2}{*}{$\mathrm{RH}$} & Median $(\mathrm{km} / \mathrm{h})$ & 132.3 & 118.5 & 117 & 114.2 & 112.7 \\
\hline & & $\begin{array}{l}\text { Standard deviation } \\
\qquad(\mathrm{km} / \mathrm{h})\end{array}$ & 0.08 & 0.10 & 0.10 & 0.08 & 0.10 \\
\hline & \multirow[b]{2}{*}{$\mathrm{RM}$} & Median $(\mathrm{km} / \mathrm{h})$ & 113.8 & 107.4 & 106.7 & 105.9 & 105.3 \\
\hline & & $\begin{array}{l}\text { Standard deviation } \\
\qquad(\mathrm{km} / \mathrm{h})\end{array}$ & 0.11 & 0.11 & 0.10 & 0.15 & 0.10 \\
\hline
\end{tabular}

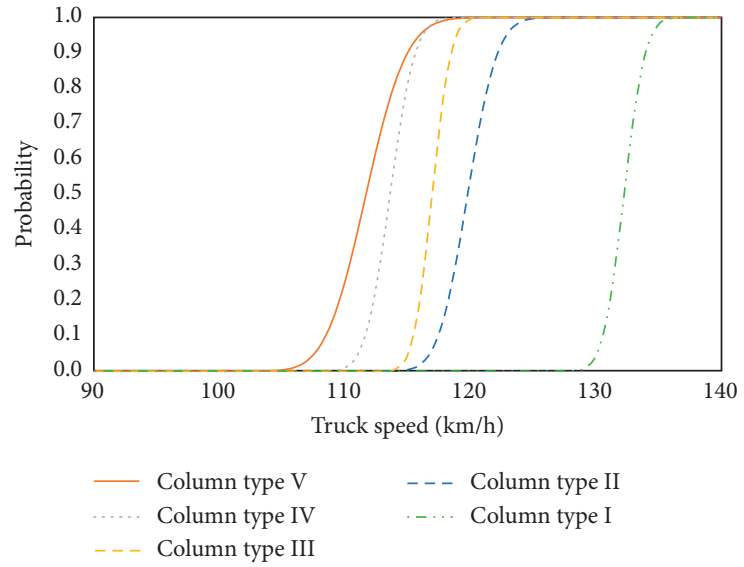

(a)

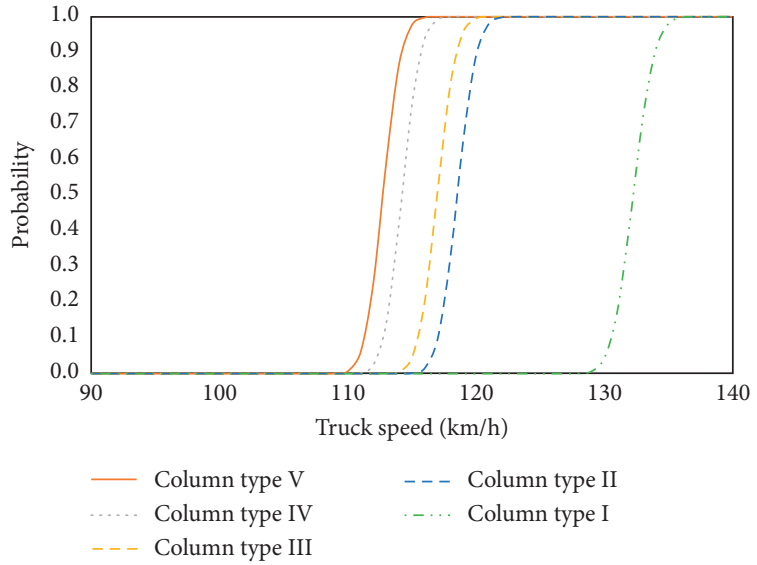

(b)

FIGURE 15: Fragility curve of 38-ton truck-bridge column collision for response high (RH). (a) Concrete compressive strength. (b) Steel rebar yield strength.

also the standard deviation value from $0.10 \mathrm{~km} / \mathrm{h}$ to $0.15 \mathrm{~km} / \mathrm{h}$ and $0.10 \mathrm{~km} / \mathrm{h}$ to $0.15 \mathrm{~km} / \mathrm{h}$ was obtained when the statistical distribution of concrete compressive strength and steel rebar yield strength was considered. The fragility curve showed greater sensitivity for the statistical distribution of concrete compressive strength compared with the statistical distribution of steel rebar yield strength. Obtained dispersions depending on the impact velocity were small number in this study since the distribution of material strength was only considered in this study. The other fragility curves with larger dispersions could be created if other distributions such as combination among various material properties (strengths, modulus of elasticity, etc.), geometric error, and reinforcement ratios are considered.

Figures 15 and 16 show the fragility curves of the typical bridge column types depending on the statistical distribution types such as concrete compressive strength and steel rebar yield strength for RH and RM response limits. For the $\mathrm{RH}$ response limit, column type $\mathrm{V}$ (slenderness ratio: 13.3) was the most vulnerable under a 38-ton truck collision, as shown in Figure 15.
For the RM response limit, column type V (slenderness ratio: 13.3) was also the most vulnerable for truck collision, and column type I (slenderness ratio: 1.9) was less vulnerable for truck collision compared with other column types.

The bridge columns ranked RLH following SRA should conform to the following procedure. Firstly, the higher risk factor between occurrence and vulnerability has to be identified. If the occurrence is a higher risk than vulnerability, as a countermeasure, the probability of a collision accident needs to be reduced. A column protector could be one good example because a protector minimizes the chance of a collision accident. If the vulnerability is a higher risk than the occurrence, as a countermeasure, a bridge column needs to be strengthened and rehabilitated against vehicle collision.

In this study, the concrete compressive strength or rebar yield strength distributions were considered separately. Therefore, for a future study, the fragility analysis that depends on the slenderness ratio and the combined effect of both distributions from concrete compressive strength and rebar yield strength, any geometric errors, and reinforcement ratios would be conducted. 


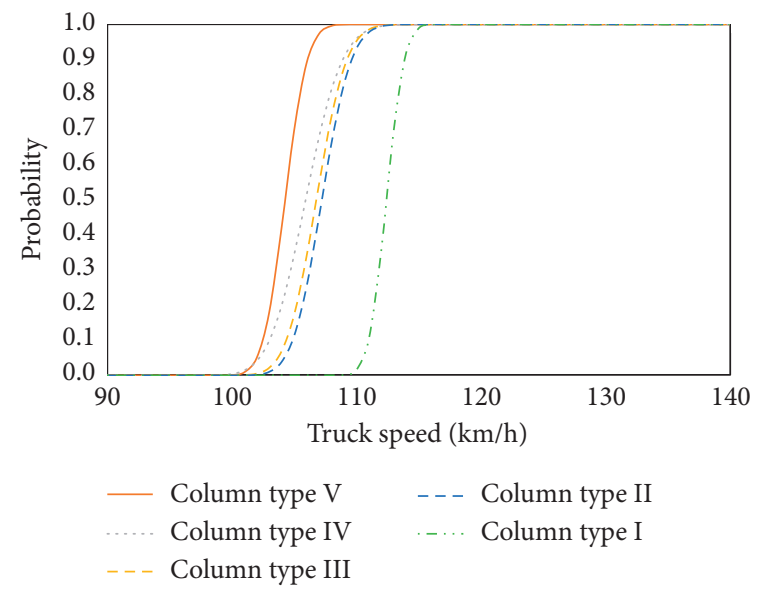

(a)

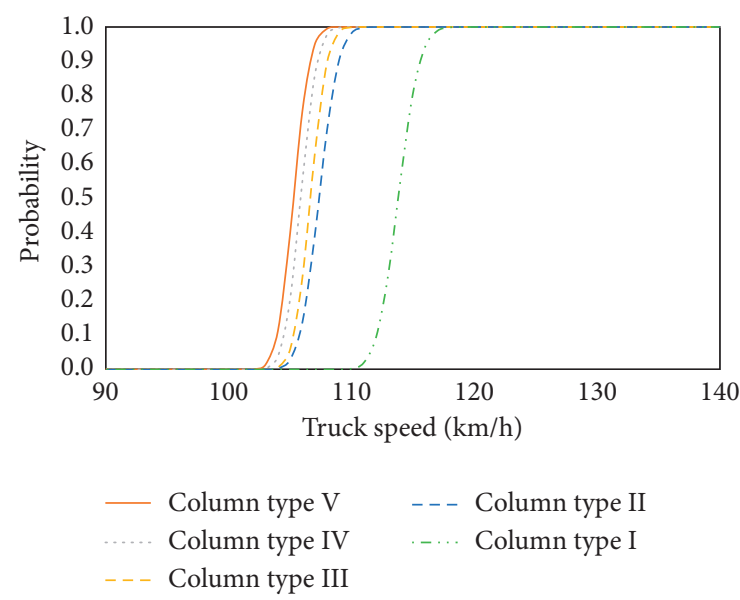

(b)

FIGURE 16: Fragility curve of 38-ton truck-bridge column collision for response moderate (RM). (a) Concrete compressive strength. (b) Steel rebar yield strength.

\section{Conclusions and Further Study}

In this study, vehicle impact risk analysis for bridge columns in South Korea was performed. Three steps, (1) Preliminary Risk Analysis (PRA), (2) Simplified Risk Analysis (SRA), and (3) Detailed Risk Analysis (DRA), were conducted, and the following conclusions were derived.

(1) The results obtained from PRA indicate that $23.1 \%$ of bridge columns in South Korea have an exposure risk for vehicle impact.

(2) In SRA, the number of bridge columns in the Risk Level High (RLH) category in the factors of occurrence and vulnerability under vehicle impact is $18.3 \%$ and $2.0 \%$, respectively.

(3) Of the total number of investigated bridge columns in South Korea, $0.7 \%$ were RLH under vehicle impact. Bridge columns in South Korea can be considered safe transportation routes under heavy vehicle impact.

(4) From the numerical analysis, the maximum cross section force of the bridge column was observed in the first impact caused by the contact of the bumper. In the second impact, column deformation was larger than the deformation in the first impact. It can be thought that the larger deformation is related to the level of force as well as to the time duration of the relatively high plateau force.

(5) The DRA results showed that column type I is not vulnerable until the $120 \mathrm{~km} / \mathrm{h}$ collision velocity of a 38 -ton truck. However, other column types prove to be more vulnerable than column type $\mathrm{I}$ as the slenderness ratio increases.

(6) There was no significant variation of support rotation until the velocity of the truck reached $110 \mathrm{~km} / \mathrm{h}$, from column type II (4.0) to type V (13.3). Column type I, on the other hand, is too short (1.9) to show similar results even though it has the same diameter and boundary conditions.

(7) If the statistical distribution of the concrete compressive strength is considered for finding the fragility curves of a bridge column under vehicle impact, column type $\mathrm{V}$ with response high $(\mathrm{RH})$ criteria showed a $111.7 \mathrm{~km} / \mathrm{h}$ median value and $0.023 \mathrm{~km} / \mathrm{h}$ dispersion value.

(8) If the statistical distribution of the steel rebar yield strength is considered for finding fragility curves of bridge column against vehicle collision, column type $\mathrm{V}$ with response high $(\mathrm{RH})$ criteria showed $112.7 \mathrm{~km} / \mathrm{h}$ median value and $0.007 \mathrm{~km} / \mathrm{h}$ dispersion value.

(9) Fragility curves were more sensitive for the statistical distribution of concrete compressive strength compared with that of the steel rebar yield strength.

\section{Data Availability}

The data used to support the findings of this study are available from the corresponding author upon request.

\section{Conflicts of Interest}

The authors declare that they have no conflicts of interest regarding the publication of this paper.

\section{Acknowledgments}

The authors gratefully acknowledge the support of Basic Science Research Program through the National Research Foundation of Korea (NRF) funded by the Ministry of Science, Information and Communication Technology (ICT) and Future Planning (2018R1A1A1A05018602).

\section{References}

[1] H. Sharma, S. Hurlebaus, and P. Gardoni, "Performancebased response evaluation of reinforced concrete columns subject to vehicle impact," International Journal of Impact Engineering, vol. 43, pp. 52-62, 2012.

[2] C. Cremona, G. Lacoste, P. Corfdir et al., "Application of risk analysis for the preservation of post-tensioned girder bridge 
decks," Bridge Maintenance, Safety, Management, Resilience and Sustainability, Chemical Rubber Company (CRC), Boca Raton, FL, USA, pp. 2885-2892, 2012.

[3] G. Min, W. Kim, J. Cho, and H. Gil, "Vehicular collision risk assessment on the highway bridges in South Korea," Journal of the Korea Institute for Structural Maintenance and Inspection, vol. 20, no. 5, pp. 9-17, 2016.

[4] Korea Expressway Corporation, Evaluation of Highway Bridge Column Based on Fire Risk Analysis, Korea Expressway Corporation, Gimcheon-si, South Korea, 2013.

[5] C. Lee, Development of the Regional Safety Assessment Model in Seoul: Focusing on Flood, Seoul Development Institute, Seoul, South Korea, 2006.

[6] Minister of Land, Infrastructure and Transport, 2013 Annual Traffic Volume Report, Minister of Land, Infrastructure and Transport, Sejong City, South Korea, 2014.

[7] Korea Road and Transportation Association, Korea Bridge Design Code, Limit State Based Bridge Design Specification, Ministry of Land, Infrastructure and Transport South Korea, Sejong City, South Korea, 2010.

[8] Korea Road and Transportation Association, Korea Bridge Design Code, Limit State Based Bridge Design Specification, Ministry of Land, Infrastructure and Transport South Korea, Sejong City, South Korea, 2016.

[9] American Association of State Highway and Transportation Officials, AASHTO LRFD Bridge Design Specifications, Customary U.S. Units, American Association of State Highway and Transportation Officials, Washington, DC, USA, 6th edition, 2012.

[10] Korea Infrastructure Safety Corporation, Detail Guideline of Safety Inspection and Precision Safety Diagnosis (Bridge) 2012, Korea Infrastructure Safety Corporation, Seoul, South Korea, 2012.

[11] J. Lee, G. Zi, I. Lee, Y. Jeong, K. Kim, and W. Kim, "Numerical simulation on concrete median barrier for reducing concrete fragment under harsh impact loading of a 25-ton truck," Journal of Engineering Materials and Technology, vol. 139, no. 2, 2017.

[12] European Committee for Normalization, EN 1317 European Standard for Road Restraint Systems, European Committee for Normalization, Brussels, Belgium, 2012.

[13] D. Y. Murray, Users Manual For Ls-Dyna Concrete Material Model 159, Federal Highway Administration, U.S. Department of Transportation, Washington, DC, USA, FHWAHRT-05-062, 2007.

[14] D. Y. Murray, A. Abu-Odeh, and R. Bligh, Evaluation of LSDYNA Concrete Material Model 159, Federal Highway Administration, U.S. Department of Transportation, Washington, DC, USA, FHWA-HRT-05-063, 2007.

[15] S. El-Tawil, E. Severino, and P. Fonseca, "Vehicle collision with bridge piers," Journal of Bridge Engineering, vol. 10, no. 3 , pp. 345-353, 2005.

[16] International Federation for Structural Concrete, FIP Model Code, International Federation for Structural Concrete, Lausanne, Switzerland, 2010.

[17] C. Chung, J. Lee, S. Kim, and J. Lee, "Influencing factors on numerical simulation of crash between RC slab and soft projectile," Journal of Computational Structural Engineering Institute of Korea, vol. 27, no. 6, pp. 533-542, 2014.

[18] Livermore Software Technology Corporation, LS-DYNA Keyword User's Manual Volume I, Livermore Software Technology Corporation (LSTC), Livermore, CA, USA, 2018.

[19] W. Kim, Y. Jeong, K. Kim, and J. Lee, "Non-linear dynamic analysis of reinforced concrete bridge columns under vehicle impact loadings," Journal of Vibroengineering, vol. 18, no. 7, pp. 4617-4626, 2016.

[20] W. Kim, K. Kim, and J. Lee, "A comparison study of direct impact analysis of vehicle to concrete pier and in-direct impact analysis using load-time history functions," Journal of Computational Structural Engineering Institute of Korea, vol. 27, no. 6, pp. 533-542, 2014.

[21] American Society of Civil Engineers (ASCE), Design of BlastResistant Buildings in Petrochemical Facilities, American Society of Civil Engineers, Reston, VA, USA, Second edition, 2010.

[22] M. Shinozuka, M. Feng, J. Lee, and T. Naganuma, "Statistical analysis of fragility curves," Journal Of Engineering Mechanic, ASCE, vol. 126, no. 12, pp. 1224-1231, 2000.

[23] M. Shinozuka, M. Q. Feng, H. Kim, T. Uzawa, and T. Ueda, Statistical Analysis of Fragility curves, Department of Civil and Environmental Engineering University of Southern California, Los Angeles, CA, USA, 2001.

[24] P. Gardoni, K. M. Mosalam, and A. D. Kiureghian, "Probabilistic seismic demand models and fragility estimates for RC bridges," Journal of Earthquake Engineering, vol. 7, no. 1, pp. 79-106, 2003.

[25] J. Kim, D. Phan, K. Lee, N. Yi, and S. Kim, "Development of PBD method for concrete mix proportion design using bayesian probabilistic method," Journal of the Korea Concrete Institute, vol. 22, no. 2, pp. 171-177, 2010.

[26] J. Kim, J. Li, J. Park, and J. Hong, "Procedure of drawing fragility curves as a function of material parameters," Korea Concrete Institute Spring Convention, Korea Concrete Institute, vol. 18, no. 1, pp. 334-337, 2010. 